Check for updates

Cite this: RSC Adv., 2019, 9, 32219

Received 21st August 2019

Accepted 25th September 2019

DOI: 10.1039/c9ra06553a

rsc.li/rsc-advances

\section{Axially chiral 1,4-dihydropyridine derivatives: aggregation-induced emission in exciplexes and application as viscosity probes $\uparrow$}

\author{
Zeren Yang, Yanmin Huo, Yanke Liu, Guifen Du, Wenhao Zhang, Lijie Zhou, \\ Lihui Zhan, Xuerui Ren, Wenzeng Duan (D)* and Shuwen Gong (DD*
}

By combining the fluorophores of axially chiral 1,1'-binaphthol (BINOL) and 1,4-dihydropyridine derivatives, axially chiral 1,4-dihydropyridine derivatives $((R)-/(S)-2)$ with aggregation-induced emission (AIE) in exciplexes were designed and synthesized. $(R)-/(S)-2$ emitted low fluorescence in THF solutions of their locally excited states; however, they emitted red-shifted fluorescence in the aggregate state upon exciplex formation. Moreover, $(R)-/(S)$-2 showed linear and multi-exponential relationships between their local excited and exciplex fluorescence intensities and the viscosity of the medium, which allowed us to determine the viscosities of different mixed solvents. In addition, as an axially chiral viscosity probe, $(R)-/$ (S)-2 show excellent CD signals and have potential applications in the fields of chiral recognition and fluorescence imaging, which will broaden the new family of AIE fluorophores. To the best of our knowledge, there are few reports of axially chiral intramolecular exciplex-mediated AIE molecules.

\section{Introduction}

Most organic fluorophores have $\pi$-conjugated aromatic rings, and they often suffer from aggregation-caused quenching $(\mathrm{ACQ})^{1}$ while aggregating in the solid state or in concentrated solutions. As an efficient strategy to overcome this ACQ effect, aggregation-induced emission (AIE) is a unique method. ${ }^{2}$ The aggregation of some organic fluorophores restricts the rotation of the aromatic rings, fixes their molecular conformations and blocks nonradiative relaxation; thus, AIE behaviors are obtained. Many AIE fluorophores, such as tetraphenylethenes, ${ }^{2}$ hexaphenylsilole ${ }^{3}$ and 9,10-di((E)-styryl)anthracene derivatives, ${ }^{4}$ have been developed. To further expand the types of AIE-active fluorophores, the development of new AIE-active fluorophores with novel frameworks and excellent photophysical properties is still an attractive topic.

The aromatic rings and amino groups in organic fluorophores can increase the probability of forming intramolecular exciplexes during molecular aggregation. ${ }^{5}$ The intramolecular exciplexes can produce intramolecular exciplex-based emissions in the long emission wavelength region, and the study of this emission region can raise the prospect of novel mechanisms of enhancing or quenching fluorescence that may differ from those produced by a simple PET mechanism. ${ }^{6}$ Although

Institute of Functional Organic Molecules and Materials, School of Chemistry and Chemical Engineering, Liaocheng University, No. 1 Hunan Road, Liaocheng, 252000, People's Republic of China. E-mail: duanwenzeng@lcu.edu.cn; gongshw@lcu.edu.cn $\dagger$ Electronic supplementary information (ESI) available. See DOI: 10.1039/c9ra06553a several examples of exciplexes are well known, ${ }^{7-9}$ the examples of exciplexes with AIE properties are extremely rare. ${ }^{10}$ Weiss et al. ${ }^{11}$ synthesized a series of $N$-alkyl- $N$-methyl-3-(pyren-1-yl) propan-1-ammonium chloride salts with spacers of propylene or butylene. Among these compounds, the compounds with propylene spacers could lead to intramolecular exciplex emissions. Intramolecular exciplex formation depends upon the conformational bending of the propenyl-chain, which separates the electron-acceptor and the electron-donor prior to the charge transfer process. ${ }^{12}$ The conformation change may be driven by hydrogen bonding, London dispersion forces, electrostatic interactions, or packing constraints imposed by the molecular shape and solvent polarity. Therefore, trimethylene tethers are known to be the most favorable for intramolecular exciplex formation. Although intramolecular exciplexes can be formed with spacers of virtually any length, ${ }^{13}$ compounds with butylene spacers show almost no discernible intramolecular exciplex fluorescence. ${ }^{14}$ The study of an intramolecular exciplex with a butylene spacer may lead to probing new conformational interactions and new applications.

BINOL and its derivatives have been studied as important sources of fluorescent materials. ${ }^{15,16}$ The electronically excited BINOL may interact with a ground-state molecule to form an intramolecular exciplex, which can lead to aggregation-induced chiral conformation changes. ${ }^{17}$ Thus, when BINOL and amino groups are linked by butylene chains, a new axially chiral intramolecular exciplex may be formed. Although axially chiral exciplex-mediated AIE molecules are important, few examples have been investigated to date. In the course of our work, we became interested in the development of AIE-active 
compounds. ${ }^{18-20}$ Herein, we attached the axially chiral BINOL to benzyl dihydropyridine through a butylene linker to afford $(R)-/$ $(S)$-2 (Scheme 1), which showed outstanding aggregationinduced emission (AIE) in exciplex fluorescence. Moreover, the effects of concentration, aggregation, and viscosity on the photophysical properties of $(R)-/(S)-2$ have been investigated.

\section{Results and discussion}

\section{Synthesis of $(R)-/(S)-2$}

$(R)-/(S)-2$ were easily obtained via a two-step procedure starting from pre-synthesized 2-(4-(bromobutoxy)phenyl)acetaldehyde ${ }^{\mathbf{2 1}}$ and $(R)-/(S)-1,1^{\prime}$-bi(2-naphthol) $((R)-/(S)$-BINOL) (Scheme 1). Firstly, compounds $(R)-/(S)-\mathbf{1}$ were easily synthesized from the nucleophilic substitution reaction of 2-(4-(bromobutoxy) phenyl)acetaldehyde, $\mathrm{KI}, \mathrm{K}_{2} \mathrm{CO}_{3}$ and $(R)-/(S)$-BINOL with a yield of $48 \% .^{22}$ Then, $(R)-/(S)-2$ were obtained from a condensation reaction with methyl 3-oxobutanoate and ammonia hydroxide in $34 \%$ yield. The structures of $(R)-/(S)-2$ were characterized by ${ }^{1} \mathrm{H},{ }^{13} \mathrm{C}$ NMR and HRMS analysis.

\section{Photophysical properties of $(R)-/(S)-2$}

The UV-vis absorption and emission spectra of $(R)-/(S)-2$ were measured in various solvents and in water/THF with varied volumetric fractions of water $\left(f_{\mathrm{w}}\right)$. In tetrahydrofuran (THF), $(R)$ - / $(S)$-2 exhibited three absorption maxima $\left(\lambda_{\mathrm{abs}}\right)$ at around $231 \mathrm{~nm}, 278 \mathrm{~nm}$ and $337 \mathrm{~nm}$, with absorption coefficients of 7400 to $11900 \mathrm{M}^{-1} \mathrm{~cm}^{-1}$ (Fig. 1 and Table 1 ). Because the $\lambda_{\text {abs }}$ of the $1,1^{\prime}$-binaphthyl unit appears at around $240 \mathrm{~nm},{ }^{23}$ the $\lambda_{\text {abs }}$ at $231 \mathrm{~nm}$ can be assigned to the $\pi-\pi^{*}$ transition of BINOL. The $\lambda_{\text {abs }}$ at $278 \mathrm{~nm}$ and $337 \mathrm{~nm}$ are assigned to the absorption of the benzyl dihydropyridine group. ${ }^{18}$ Correspondingly, $(R)-/(S)-2$ emit at $371 \mathrm{~nm}$ and $375 \mathrm{~nm}$ in THF with moderate fluorescence quantum yields $\left(\Phi_{\mathrm{f}}=15 \%\right.$ for $(R)-2$ and $14 \%$ for $(S)-2$, respectively). These observations can be attributed to the intermolecular interactions between "binol" and "binol" or "benzyl dihydropyridine" and "benzyl dihydropyridine", which restrict the free rotation of BINOL and the 1,4-dihydropyridine group

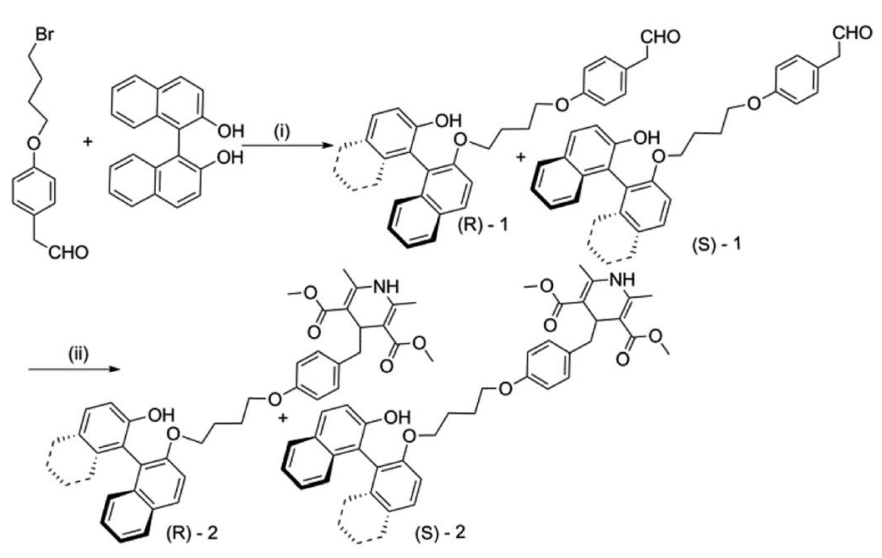

Scheme 1 Synthetic routes for $(R)-/(S)-2$. Reaction conditions: (i) $\mathrm{K}_{2} \mathrm{CO}_{3}$ (5.0 equiv.), $\mathrm{Kl}$ (0.3 equiv.), $\mathrm{CH}_{3} \mathrm{CN}$, reflux, $20 \mathrm{~h}$; (ii) methyl 3oxobutanoate (2.0 equiv.), ammonia (10.0 equiv.), EtOH, reflux, $48 \mathrm{~h}$.

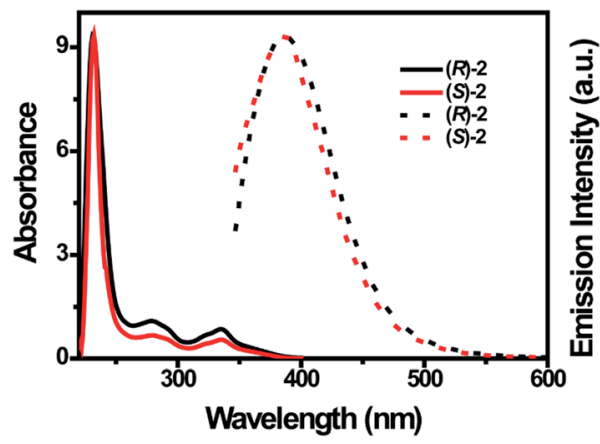

Fig. 1 Absorption and emission spectra of $(R)-/(S)-2(50 \mu \mathrm{M})$ in THF.

and block the nonradiative decay pathways. Moreover, the Stokes shifts of $(R)-/(S)-2$ are 2631 and $3095 \mathrm{~cm}^{-1}$ in THF, respectively, which indicates that $(R)-/(S)$-2 have weak selfabsorption and can be used as effective luminophores.

In different solvents, the solvent effects on the absorption and emission spectra of $(R)-/(S)-2$ were also investigated. As the solvent varies from hexane to glycol, the peak positions and patterns of the absorption spectra of $(R)-/(S)-2$ show no noticeable changes (Fig. S1†), indicating that the ground state is hardly affected by the solvent polarity and viscosity. Meanwhile, the emission spectra in the local excited state (LE) of $(R)-/(S)-2$ show almost same the peak positions and patterns at the wavelengths between $350 \mathrm{~nm}$ to $400 \mathrm{~nm}$ from hexane to dimethylformamide (DMF). Interestingly, in glycol, a new emission band $\left(\lambda_{\mathrm{em}}\right)$ at $425 \mathrm{~nm}$ with stronger fluorescence intensity is observed (Fig. 2).

The new $\lambda_{\text {em }}$ may be due to the effect of the viscosity of the medium and is a feature associated with intramolecular exciplex formation. ${ }^{\mathbf{1 4}}$ The intramolecular exciplex is an excited state complex which may be formed by BINOL and dimethyl 4-benzyl2,6-dimethyl-1,4-hydropyridine-3,5-dicarboxylate through the tetramethylene linker. While in solution, $(R)-/(S)-2$ can be considered to exist in an equilibrium between two extreme conformations: an open (O) conformation with the butylenechain extended completely away from the BINOL group and the benzyl dihydropyridine center, and a closed (C) conformation in which the proton on the nitrogen atom from the dihydropyridine and the proton on the oxygen atom from BINOL may be pointed toward the aromatic $\pi$-electrons, ${ }^{12}$ forming intramolecular interactions (Scheme S1 $\dagger$ ). As the viscosity increases, the conformation $\mathrm{C}$ increases. Therefore, the emission bands in glycol consist of comparable amounts of LE and exciplex emissions. In order to certify the exciplex formation, we applied different excitation wavelengths from $330 \mathrm{~nm}$ to $338 \mathrm{~nm}$ in steps of $2 \mathrm{~nm}$ (Fig. $\mathrm{S} 2 \dagger$ ), and we found that the emission spectrum of $(R)-2$ shows a gradual decrease in the intensity of its LE emission and a gradual increase in the intensity of its exciplex emission. This result is consistent with the increasing amount of conformation $\mathrm{C}$, which leads to exciplex formation. ${ }^{24,25}$ Meanwhile, we performed molecular dynamic simulations to study the conformational changes of $(R)-2$ in pure THF solution and in a THF/water mixture. The initial configuration 
Table 1 Photophysical data of $(R)-/(S)-2$ in solution and in the solid state

In solution

Cpd $\quad \lambda_{\mathrm{abs}}{ }^{a}(\mathrm{~nm}) \varepsilon\left(\mathrm{mol}^{-1} \mathrm{~cm}^{-1}\right)$

$(R)-2 \quad 278(11900) / 337(9400)$

(S)-2 $278(10000) / 337(7400)$ $\lambda_{\mathrm{em}}{ }^{a}(\mathrm{~nm})\left(\Phi_{\mathrm{f}}\right)$ solu.

$371(15 \%)$

$375(14 \%)$
In solid-state

$\lambda_{\text {abs }}$

$(\mathrm{nm})$

$275 / 330$

$275 / 330$

$431(42 \%)$

$432(40 \%)$

3095

422

3934

3916

${ }^{a}$ Measured at a concentration of $50 \mu \mathrm{M}$ in THF at $25^{\circ} \mathrm{C} .{ }^{b}$ Determined using 4-methylamino-7-nitro-2,1,3-benzoxadiazole $\left(\Phi_{\mathrm{f}}=0.38\right.$ in acetonitrile $)$ as a reference..$^{36}$ Measured at a concentration of $50 \mu \mathrm{M}$ in a THF/ $\mathrm{H}_{2} \mathrm{O}$ mixture with a $f_{\mathrm{w}}$ of $80 \%$ at $25{ }^{\circ} \mathrm{C}$. ${ }^{d}$ Frequency units between the longest absorption band and emission band.
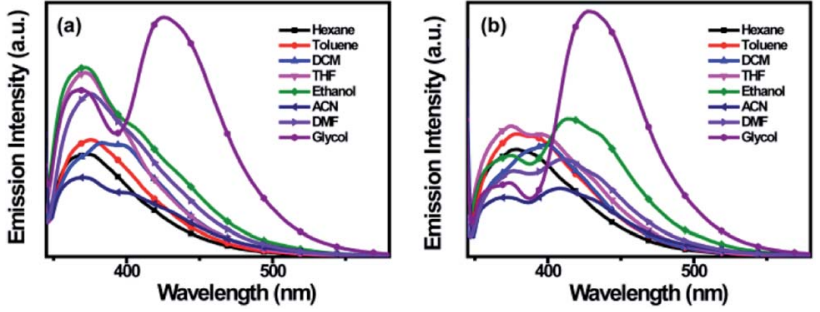

Fig. 2 Emission spectra of compounds $(R)-2(a)$ and $(S)-2(b)$ in various solvents $(50 \mu \mathrm{M})$, namely hexane, toluene, dichloromethane (DCM), tetrahydrofuran (THF), ethanol, acetonitrile (ACN), dimethylformamide (DMF) and ethylene glycol (glycol).

at 0 ns was constructed by randomly inserting conformation $\mathrm{O}$ molecules into pure THF solution and the THF/water mixture. After $1 \mathrm{~ns}$ of simulation, the conformation $\mathrm{O}$ in pure $\mathrm{THF}$ showed almost no change, except that aggregation occurred (Fig. S3 $\dagger$ ). In contrast, in the THF/water mixture, after 1 ns of simulation, the conformation $\mathrm{C}$ was formed, which proved that these two conformations both exist in the THF/water mixture (Fig. S4 $\dagger$ ). The TD-DFT calculations were also carried out at the B3LYP/6-31G(d) level with the Gaussian 03 program package ${ }^{26}$ to predict the $\lambda_{\mathrm{em}}$ of the conformation $\mathrm{C}$. According to the theoretical calculation results, ${ }^{27,28}$ the $\lambda_{\text {em }}$ of conformation $\mathrm{C}$ is $414 \mathrm{~nm}$ (Fig. S5 and S6 ${ }^{\dagger}$ ), which is almost completely consistent with the exciplex emission. Therefore, the obtained data confirm the exciplex formation between the BINOL group and the dihydropyridine group in $(R) /(S)-2$. Moreover, upon changing the solvent from hexane to DMF, $(R) /(S)-2$ showed little or no exciplex emission, which indicates that the solvent polarity has little impact on the exciplex formation. Because the formation of an exciplex requires a highly concentrated medium, the emission properties of $(R)-/(S)-2$ in mixed solvent systems of THF- $\mathrm{H}_{2} \mathrm{O}$ with varied $f_{\mathrm{w}}$ were also investigated.

\section{Photophysical properties in the aggregated state}

As shown in Fig. 3, in THF solution, $(R)-/(S)-2$ show only LE $\lambda_{\mathrm{em}}$ with low emission intensities. As the content of water in THF increased from $0 \%$ to $80 \%$, the emission intensity of the LE $\lambda_{\mathrm{em}}$ was gradually quenched and reached the minimum when the $f_{\mathrm{w}}$ exceeded $80 \%$. This phenomenon can be explained by the decrease of the conformers with LE $\lambda_{\mathrm{em}}$ as the aggregation proceeds; as the $f_{\mathrm{w}}$ reached $80 \%$, the conformers with $\mathrm{LE} \lambda_{\mathrm{em}}$ almost vanished. In contrast, as the $f_{\mathrm{w}}$ increased from $0 \%$ to $70 \%$, the emission intensity of exciplex $\lambda_{\mathrm{em}}$ showed almost no obvious enhancement; however, it suddenly increased dramatically when the $f_{\mathrm{w}}$ exceeded $70 \%$. As the $f_{\mathrm{w}}$ increased from $80 \%$ to $99 \%$, the emission spectra of $(R)-/(S)-2$ were dominated by the exciplex emission. As the $f_{\mathrm{w}}$ reached $99 \%$, the emission intensities of $(R)-/(S)$-2 were 11- and 13-fold higher than those in 10\% $\mathrm{H}_{2} \mathrm{O}$-THF solution. Obviously, as the $f_{\mathrm{w}}$ increased, the locally excited (LE) $\lambda_{\text {em }}$ showed ACQ and the exciplex $\lambda_{\text {em }}$ exhibited AIE character. The reason for this result may be conformation changes. As water was added to the THF solution, the amount of $\mathrm{O}$ conformer for $\mathrm{LE} \lambda_{\mathrm{em}}$ decreased gradually, which caused quenching of the LE emission intensity. In contrast, the hydrophobicity of $(R)-/(S)-2$ enhanced the formation of the $\mathrm{C}$ conformer; the $\mathrm{O}$ conformer could be gradually deconvoluted into the $\mathrm{C}$ conformer, which led to the exciplex formation (Scheme $\mathrm{S} 1 \dagger$ ). Indeed, the $\mathrm{C}$ conformer is the more probable conformer because of the tetramethylene linker. ${ }^{29}$ As the proportion of $\mathrm{C}$ conformer increases gradually, the emission intensity of exciplex $\lambda_{\mathrm{em}}$ is gradually enhanced. When the $f_{\mathrm{w}}$ exceeds $80 \%$, the intramolecular rotation is also restricted,
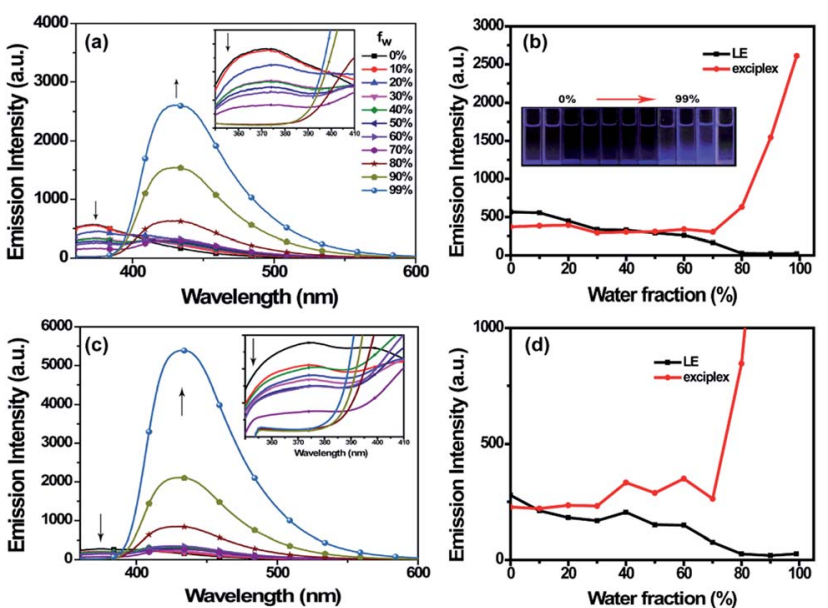

Fig. 3 Emission spectra of $(R)-2$ (a) and (S)-2 (c) in water/THF (50 $\mu \mathrm{M})$ with varied volumetric fractions of water $\left(f_{\mathrm{w}}\right)$; (b) plots of the emission intensity at $431 \mathrm{~nm}$ of $(R)-2$ and (d) at $432 \mathrm{~nm}$ of (S)-2 in the water/THF mixtures. The insets in ( $a$ and $c$ ) are enlarged views of the local excited emissions; the inset in (b) shows fluorescence photographs of (R)-2 in water/THF $(50 \mu \mathrm{M})$ with different $f_{\mathrm{w}}$ taken under $365 \mathrm{~nm}$ UV irradiation. $\lambda_{\text {ex }}=338 \mathrm{~nm}$. 
which fixes the molecular conformation and blocks the nonradiative path; this causes the emission intensities of $(R)-/(S)-2$ to increase significantly. Thus, the O conformer for LE emission is identified as probably having the lowest energy for the THF solutions of $(R)-/(S)$-2. As water was added, the C conformer formed and equilibrated with increasing viscosity. Although the excited state equilibrium of the conformation change has an influence on the change of $\lambda_{\mathrm{em}}$, it has a limited contribution to the dramatic increase of the fluorescence intensity of the exciplex $\lambda_{\text {em }}$. The aggregation of $(R)-\left((S)-2\right.$ at high values $\left(f_{\mathrm{w}} \geq 80 \%\right)$ can restrict the intramolecular free rotation of the aromatic and dihydropyridine rings, which results in AIE properties of $(R)-1$ $(S)-2$ in exciplexes. Additionally, the absorptions of $(R)-/(S)-2$ show a gradual decrease with almost the same peak position and pattern; upon further increases in $f_{\mathrm{w}}$ to $90 \%$ and $99 \%$, the intensities of the absorbance bands almost vanished, which also suggests that the aggregated state is formed gradually (Fig. S7† $†$ ) ${ }^{30}$ Moreover, changes in the fluorescence colors under UV irradiation ( $365 \mathrm{~nm}$ ) from bright navy blue to dark navy blue and then to bright navy blue were observed with the change of $f_{\mathrm{w}}$ (Fig. 3b). Furthermore, as shown in Fig. S8, $\uparrow$ the exciplex fluorescence of $(R)$-2 was not observed in THF/hexane mixtures with different hexane fractions (from $0 \%$ to $90 \%$ ), which implies that the exciplex emission can be observed in hydrogen-bond accepting solvents with relatively high viscosities (glycol, glycerol-methanol). Additionally, we examined the emission spectra of $(R)-/(S)-2$ at different concentrations. ${ }^{31}$ With increasing concentration from $1 \times 10^{-5} \mathrm{M}$ to $1 \times 10^{-3} \mathrm{M}$ (Fig. S9†), only LE $\lambda_{\text {em }}$ were observed as the emission intensities increased dramatically and then decreased. Consistent with the increasing viscosity, the exciplex $\lambda_{\mathrm{em}}$ occurred at the concentration of $1 \times 10^{-2} \mathrm{M}$, indicating that a high concentration can also generate exciplex $\lambda_{\mathrm{em}}$. Therefore, as the concentration increases, the conformation $\mathrm{C}$ increases gradually, which leads to exciplex $\lambda_{\mathrm{em}}$.

\section{Viscosity-dependent emission}

In viscous solution, $(R)-/(S)-2$ have the equilibrium of conformation $\mathrm{O}$ and conformation $\mathrm{C}$, which causes the $\mathrm{LE} \lambda_{\mathrm{em}}$ and exciplex $\lambda_{\mathrm{em}}$. Because the exciplex $\lambda_{\mathrm{em}}$ has AIE properties, it can provide a means to quantify viscosity. In fact, the LE $\lambda_{\mathrm{em}}$ and exciplex $\lambda_{\mathrm{em}}$ may sense viscosity changes and can act as a viscosity probe. ${ }^{32}$ Thus, their viscosity-dependent emission behavior was investigated by adding glycerol to a solution of $(R) /(S)-2$ in methanol (50 $\mu \mathrm{M}) .^{33}$ Interestingly, the two emission bands were both significantly influenced. For $\mathrm{LE} \lambda_{\mathrm{em}}$, while increasing the viscosity of the solution of $(R)-/(S)-2$ by increasing the volumetric fraction of glycerol from $0 \%$ to $80 \%$, the emission intensities increased steadily; the slopes of the fitted straight lines are 0.40023 and 0.09775 (Fig. 4b and d), and the detection limits of $(R)-/(S)-2$ for glycerol are 1.3 and 5.5, respectively. Meanwhile, for exciplex $\lambda_{\mathrm{em}}$, the emission intensities also increased gradually as the volumetric fraction of glycerol increased from $0 \%$ to $80 \%$, and the relationships were multi-exponential (Fig. $4 \mathrm{~b}$ and d). The emission intensities of $(R)-/(S)$-2 were enhanced 2-fold for LE $\lambda_{\text {em }}$ and 11 -fold for exciplex $\lambda_{\text {em }}$ compared with those in $10 \%$ glycerol-
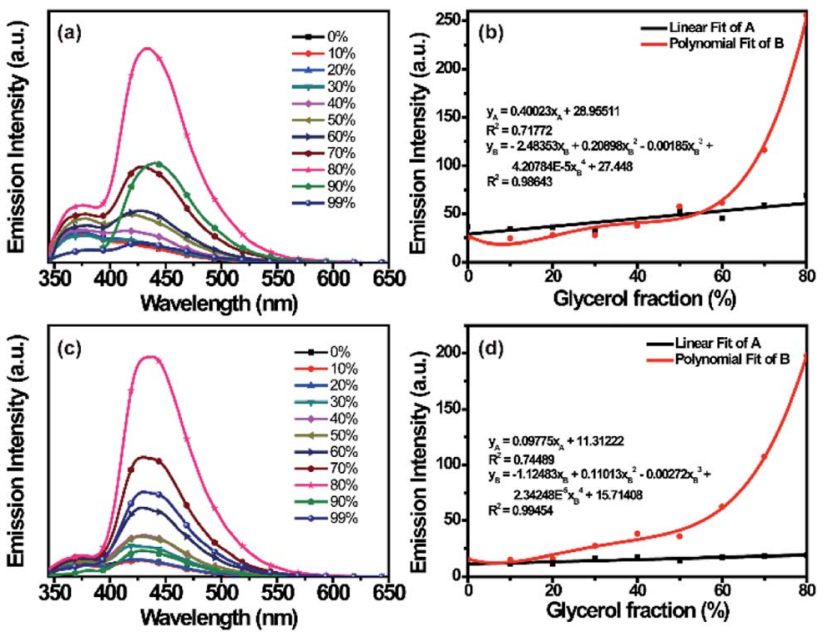

Fig. 4 Emission spectra of (R)-2 (a) and (S)-2 (c) in glycerol/methanol $(50 \mu \mathrm{M})$ with varied volumetric fractions of glycerol; calibration curves of the emission intensities at $372 \mathrm{~nm}$ and $431 \mathrm{~nm}$ of $(R)-2(\mathrm{~b})$ and at $375 \mathrm{~nm}$ and $432 \mathrm{~nm}$ of (S)-2 (d) in solutions with increasing viscosity. The meanings of $A$ and $B$ in ( $b$ and $d$ ) are A: LE $\lambda_{e m}$ and $B$ : exciplex $\lambda_{e m}$.

methanol solution. Therefore, as the volumetric fraction of glycerol increased from $0 \%$ to $80 \%$, the fitted straight lines of the two emission bands showed relatively high correlation coefficients, indicating that $(R)-/(S)-2$ can be used as a ratiometric sensor to detect the viscosity of glycerol-methanol solution. However, as the volumetric fraction of glycerol in the glycerolmethanol solution increased from $80 \%$ to $99 \%$, the emission intensities of $(R)-/(S)$-2 both decreased as precipitation occurred in the viscous solution.

Subsequently, we examined the absorption and fluorescence properties of $(R)-((S)-2$ in the solid state (Fig. S10 $\dagger$ and Table 1). The absorption bands of $(R)-/(S)-2$ in the solid state are almost the same (275 $\mathrm{nm}$ and $330 \mathrm{~nm}$ ) as the corresponding absorption bands in solution ( $278 \mathrm{~nm}$ and $337 \mathrm{~nm}$ ). In contrast, the emission bands of $(R)-((S)-2$ are red-shifted ( $422 \mathrm{~nm}$ and $422 \mathrm{~nm})$ compared with those in solution ( $371 \mathrm{~nm}$ and $375 \mathrm{~nm}$ ). Obviously, the emission band in the solid state is also an exciplex $\lambda_{\mathrm{em}}$, and the solid state can also afford the exciplex $\lambda_{\mathrm{em}}$. Accordingly, the powders of $(R)-/(S)-2$ emit cyan fluorescence (Fig. S10b $\dagger$ ). The intense emissions and different emission properties of $(R)-/(S)-2$ indicate that they have potential applications as high efficiency luminescent materials in the solid state.

\section{Chiroptical properties}

The corresponding chiroptical properties of $(R)-/(S)$-2 were also investigated by CD spectroscopy (Fig. 5 ). In the CD spectra, the chirality of $(R)-/(S)-2$ mainly arises from the BINOL moiety; because the length between BINOL and dihydropyridine is longer in solution, the $\lambda_{\text {abs }}$ at $278 \mathrm{~nm}$ and $337 \mathrm{~nm}$ are weak. The CD signal generated by the $1,1^{\prime}$-binaphthyl unit was observed at around $240 \mathrm{~nm}$ because of the $\lambda_{\text {abs }}$ of the $1,1^{\prime}$-binaphthyl unit; thus, we can judge the $R$ and $S$ configurations of $(R)-/(S)-2$ to be right- and left-handed conformers, respectively.$^{20}$ Obviously, the CD signals of $(R)-2$ change from positive to negative and those of 


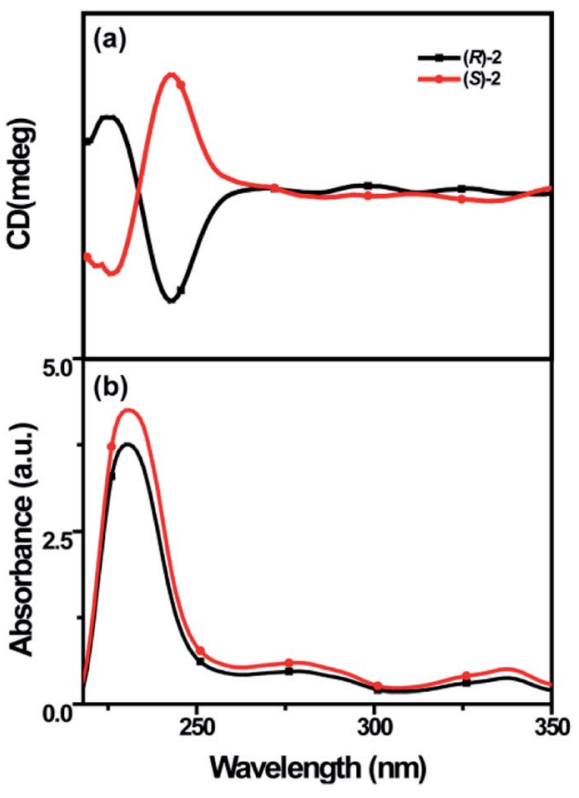

Fig. $5 \mathrm{CD}$ spectra of compounds $(R) /(S)-2$ in THF $(50 \mu \mathrm{M})$.

$(S)$-2 change from negative to positive in this region, which indicates that $(R)-2$ is the right-handed conformer and $(S)-2$ is the left-handed conformer. This result is consistent with the specific optical rotations of $(R)-/(S)-2$. Moreover, the CD spectrum of $(R)-2$ exhibits negative Cotton effects at 224 and $237 \mathrm{~nm}$, and $(S)-2$ displays a nearly perfect mirror image of the CD spectrum of $(R)$-2. The absorption dissymmetry factors $\left(g_{\mathrm{abs}}=\right.$
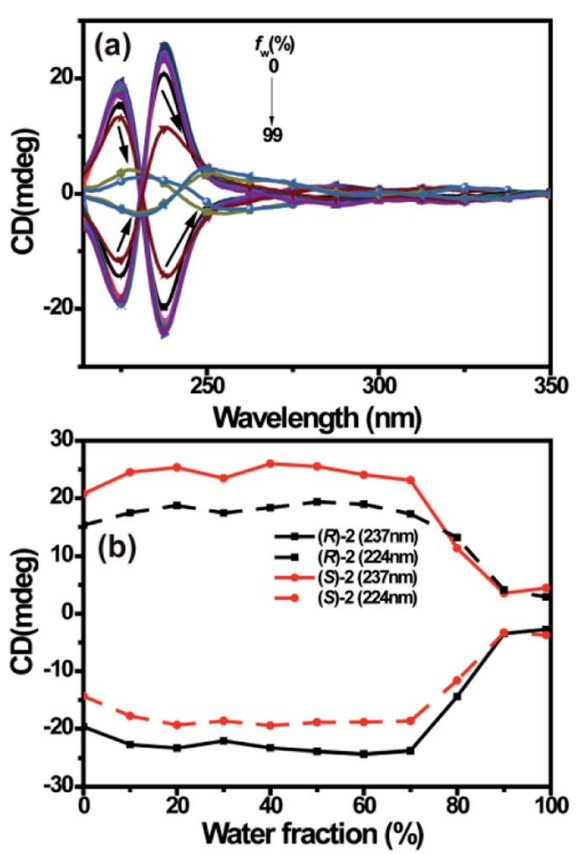

Fig. 6 (a) CD spectra of $(R) /(S)-2$ in water/THF $(50 \mu \mathrm{M})$ with varied volumetric fractions of water $\left(f_{\mathrm{w}}\right)$; (b) plots of the relative molar ellipticities of $(R)-2$ at $237 \mathrm{~nm}$ and $224 \mathrm{~nm}$ and of (S)-2 at $237 \mathrm{~nm}$ and $224 \mathrm{~nm}$ versus $f_{\mathrm{w}}$.
$\left.\left(\varepsilon_{\mathrm{L}}-\varepsilon_{\mathrm{R}}\right) /\left(\varepsilon_{\mathrm{L}}+\varepsilon_{\mathrm{R}}\right) / 2\right)$ at $231 \mathrm{~nm}$ are about $-0.62 \times 10^{-4}$ for $(R)-2$ and $0.56 \times 10^{-4}$ for $(S)$-2. Also, we measured the CD spectra of $(R)-/(S)-2$ in $\mathrm{H}_{2} \mathrm{O}-\mathrm{THF}$ solutions with different $f_{\mathrm{w}}$. As the $f_{\mathrm{w}}$ increased from $0 \%$ to $70 \%$, the CD signals showed almost no obvious change; however, they suddenly collapsed at $80 \%$ with red-shifted $\lambda_{\text {cd }}$ ( 8 and $19 \mathrm{~nm}$ ) as $f_{\mathrm{w}}$ increased to $90 \%$. Upon further increasing $f_{\mathrm{w}}$ from $90 \%$ to $99 \%$, the CD signals remained constant at low values; this is the aggregation annihilation circular dichroism (AACD) phenomenon, and $(R)-/(S)-2$ showed the AACD effect (Fig. 6). ${ }^{34,35}$ Therefore, the 1,4-dihydropyridine chromophore bearing the axially chiral BINOL group has potential applications in chiral sensing.

\section{Conclusions}

In summary, axially chiral 1,4-dihydropyridine derivatives $((R)-/$ $(S)$-2) were synthesized and characterized. The compounds $(R)$-/ $(S)-2$ show low fluorescence of the locally excited state in THF solution and AIE enhancement of exciplex fluorescence in the aggregate state. Due to the linear relationships between the local excited and exciplex fluorescence intensities and the media viscosity, $(R)-/(S)-2$ can be used to quantitatively detect the solution viscosity of mixed solvents. In addition, as an axially chiral viscosity probe, $(R)-/(S)-2$ have excellent CD signals and have potential applications in the probe for monitoring viscosity changes in aqueous biological system, which will broaden the new family of AIE fluorophores.

\section{Experiments}

\section{General information}

All the solvents were of analytical grade. Column flash chromatography was carried out on silica gel (200 to 400 mesh). Thin-layer chromatography (TLC) was performed on GF254 silica gel. The fluorescence spectra were measured on a F-4600 spectrofluorimeter (Hitachi, Japan) luminescence spectrophotometer (the path length of the quartz cell was $1 \mathrm{~cm}$ ) with a xenon arc lamp as the light source. Absorbance spectra measurements were performed on a T9CS UV-vis spectrophotometer (Persee Instrument Co., Ltd. Beijing, China). ${ }^{1} \mathrm{H}$ and ${ }^{13} \mathrm{C}$ NMR spectra were recorded on a Varian Mercury-plus $400 \mathrm{MHz}$ spectrometer/a Bruker Avance NEO $500 \mathrm{MHz}$ spectrometer and were referenced to the residual proton signals of the solvent. HRMS spectra were recorded on a Waters G2-XS QTOF spectrometer.

\section{Synthesis}

Unless otherwise noted, the following conditions were used for all non-aqueous reactions. Compounds $(R)-/(S)-2$ were readily prepared according to Scheme 1.

Compounds $(\boldsymbol{R})-/(\boldsymbol{S})$-1. 2-(4-(Bromobutoxy)phenyl)acetaldehyde (1.2 g, $4.6 \mathrm{mmol})$ and $(R)-/(S)-1,1^{\prime}$-bi(2-naphthol) (1.3 g, 4.6 $\mathrm{mmol})$ were dissolved in anhydrous acetonitrile $(30 \mathrm{~mL})$. After that, $\mathrm{KI}(0.23 \mathrm{~g}, 1.4 \mathrm{mmol})$ and $\mathrm{K}_{2} \mathrm{CO}_{3}(3.2 \mathrm{~g}, 23.0 \mathrm{mmol})$ were added, and the reaction solution was refluxed under argon for 20 hours. After completion of the reaction, the reaction solution 
was cooled and the solvent was evaporated. The crude product was purified by column chromatography on silica gel (petroleum ether : ethyl acetate $=2: 1$ ) to afford the yellow solid compounds $(R)-/(S)$-1. Yield: $48 \%$.

(S)-1. ${ }^{1} \mathrm{H}$ NMR $\left(500 \mathrm{MHz}, \mathrm{CDCl}_{3}\right) \delta 9.79(\mathrm{~s}, 1 \mathrm{H}), 7.96(\mathrm{~d}, J=$ $9.0 \mathrm{~Hz}, 1 \mathrm{H}), 7.83(\mathrm{~d}, J=8.0 \mathrm{~Hz}, 1 \mathrm{H}), 7.79(\mathrm{~d}, J=8.9 \mathrm{~Hz}, 1 \mathrm{H}), 7.75$ $(\mathrm{d}, J=8.1 \mathrm{~Hz}, 1 \mathrm{H}), 7.72-7.67$ (m, 1H), 7.41-7.37 (m, 1H), 7.347.29 (m, 1H), 7.27-7.20 (m, 3H), 7.17-7.11 (m, 2H), 7.01-6.96 $(\mathrm{m}, 1 \mathrm{H}), 6.69(\mathrm{~d}, J=8.7 \mathrm{~Hz}, 1 \mathrm{H}), 4.91(\mathrm{~d}, J=8.8 \mathrm{~Hz}, 1 \mathrm{H}), 4.03$ (ddd, $J=9.2,6.5,5.2 \mathrm{~Hz}, 1 \mathrm{H}), 3.98-3.91(\mathrm{~m}, 1 \mathrm{H}), 3.55-3.41(\mathrm{~m}$, 2H), 1.64-1.52 (m, 2H), 1.42-1.32 (m, 2H), 1.19 (s, 2H); ${ }^{13} \mathrm{C}$ NMR $\left(126 \mathrm{MHz}, \mathrm{CDCl}_{3}\right) \delta 189.80,163.01,154.37,150.28,133.00$, 132.81, 130.87, 130.01, 129.20, 128.71, 128.69, 128.06, 127.17, $127.07,126.33,125.35,124.01,123.86,123.43,122.19,116.43$, 115.65, 114.80, 114.15, 113.67, 76.20, 68.36, 66.41, 24.59, 24.25; HRMS $\left(\mathrm{ESI}^{+}\right) \mathrm{m} / z$ calculated for $\mathrm{C}_{32} \mathrm{H}_{28} \mathrm{O}_{4}:[\mathrm{M}+\mathrm{Na}]^{+}=499.1885$, found: $[\mathrm{M}+\mathrm{Na}]^{+}=499.1831$.

Compounds $(\boldsymbol{R})-/(S)-2$. Compound $(R)-1$ or $(S)-1$ (1.0 g, 2.2 $\mathrm{mmol})$, methyl 3-oxobutanoate $(0.51 \mathrm{~g}, 4.4 \mathrm{mmol})$ and $25 \%$ ammonia aqueous solution ( $0.34 \mathrm{~mL}, 2.2 \mathrm{mmol})$ were dissolved in $20 \mathrm{~mL}$ ethanol and refluxed under argon for 48 hours. After completion of the reaction, the reaction solution was cooled and the solvent was evaporated. The crude product was purified by column chromatography on silica gel (petroleum ether: ethyl acetate $=2: 1)$ to afford the white solid compounds $(R)$-/ $(S)$-2. Yield: $34 \%$.

(R)-2. $[\alpha]_{\mathrm{D}}^{25} 128\left(c 0.05, \mathrm{CH}_{2} \mathrm{Cl}_{2}\right) ;{ }^{1} \mathrm{H}$ NMR (400 MHz, $\left.\mathrm{CDCl}_{3}\right)$ $\delta 8.02(\mathrm{~d}, J=9.1 \mathrm{~Hz}, 1 \mathrm{H}), 7.86(\mathrm{dt}, J=20.1,9.4 \mathrm{~Hz}, 3 \mathrm{H}), 7.45(\mathrm{~d}, J$ $=9.0 \mathrm{~Hz}, 1 \mathrm{H}), 7.38(\mathrm{t}, J=7.4 \mathrm{~Hz}, 1 \mathrm{H}), 7.29(\mathrm{dd}, J=16.2,8.6 \mathrm{~Hz}$, $4 \mathrm{H}), 7.24-7.16(\mathrm{~m}, 2 \mathrm{H}), 7.12(\mathrm{~d}, J=8.4 \mathrm{~Hz}, 2 \mathrm{H}), 7.04(\mathrm{~d}, J=$ $8.4 \mathrm{~Hz}, 1 \mathrm{H}), 6.57$ (d, $J=8.4 \mathrm{~Hz}, 2 \mathrm{H}), 5.58(\mathrm{~d}, J=13.3 \mathrm{~Hz}, 1 \mathrm{H})$, $4.98(\mathrm{~s}, 1 \mathrm{H}), 4.92(\mathrm{~s}, 1 \mathrm{H}), 4.03(\mathrm{~d}, J=27.3 \mathrm{~Hz}, 3 \mathrm{H}), 3.64(\mathrm{~s}, 5 \mathrm{H})$, $3.52(\mathrm{~d}, J=5.7 \mathrm{~Hz}, 2 \mathrm{H}), 2.33$ (s, 6H), 1.69-1.53 (m, 3H), 1.44-1.21 $(\mathrm{m}, 4 \mathrm{H}) ;{ }^{13} \mathrm{C}$ NMR $\left(101 \mathrm{MHz}, \mathrm{CDCl}_{3}\right) \delta 168.07,157.31,155.40$, 151.22, 143.82, 139.63, 133.98, 133.77, 130.91, 129.68, 129.58, 129.02, 128.67, 128.48, 128.14, 128.04, 127.21, 126.28, 125.00, $124.85,124.26,123.12$, 117.41, 115.74, 113.82, 113.73, 104.14, $69.23,66.72,59.50,51.00,38.35,25.78,25.24,19.65$; HRMS $\left(\mathrm{ESI}^{+}\right) \mathrm{m} / \mathrm{z}$ calculated for $\mathrm{C}_{42} \mathrm{H}_{41} \mathrm{NO}_{7}:[\mathrm{M}+\mathrm{Na}]^{+}=694.2781,[\mathrm{M}+$ $\mathrm{K}]^{+}=710.2520$, found: $[\mathrm{M}+\mathrm{Na}]^{+}=694.2825,[\mathrm{M}+\mathrm{K}]^{+}=$ 694.2531.

(S)-2. $[\alpha]_{\mathrm{D}}^{25}-86\left(c 0.05, \mathrm{CH}_{2} \mathrm{Cl}_{2}\right) ;{ }^{1} \mathrm{H}$ NMR (500 MHz, $\left.\mathrm{CDCl}_{3}\right)$ $\delta 7.95(\mathrm{~d}, J=9.0 \mathrm{~Hz}, 1 \mathrm{H}), 7.83(\mathrm{~d}, J=8.2 \mathrm{~Hz}, 1 \mathrm{H}), 7.76(\mathrm{dd}, J=$ 14.5, 8.5 Hz, 2H), 7.39 (d, $J=9.1 \mathrm{~Hz}, 1 \mathrm{H}), 7.31(\mathrm{t}, J=7.0 \mathrm{~Hz}, 1 \mathrm{H})$, $7.26-7.20(\mathrm{~m}, 3 \mathrm{H}), 7.13$ (dd, $J=15.5,7.7 \mathrm{~Hz}, 2 \mathrm{H}), 7.05$ (dd, $J=$ $8.6,4.4 \mathrm{~Hz}, 2 \mathrm{H}), 6.97$ (d, $J=8.6 \mathrm{~Hz}, 1 \mathrm{H}), 6.50(\mathrm{~d}, J=8.6 \mathrm{~Hz}, 2 \mathrm{H})$, $5.47(\mathrm{~d}, J=15.4 \mathrm{~Hz}, 1 \mathrm{H}), 4.91-4.81(\mathrm{~m}, 2 \mathrm{H}), 4.01(\mathrm{ddd}, J=15.2$, $11.1,6.4 \mathrm{~Hz}, 2 \mathrm{H}), 3.91(\mathrm{dt}, J=9.3,6.2 \mathrm{~Hz}, 1 \mathrm{H}), 3.57$ (d, $J=3.6 \mathrm{~Hz}$, $4 \mathrm{H}), 3.45$ (qt, $J=15.2,7.5 \mathrm{~Hz}, 2 \mathrm{H}), 2.26$ (d, $J=2.8 \mathrm{~Hz}, 5 \mathrm{H}), 1.56$ (dq, $J=13.7,7.5 \mathrm{~Hz}, 2 \mathrm{H}), 1.32$ (ddd, $J=21.2,14.0,7.4 \mathrm{~Hz}, 2 \mathrm{H}$ ), 1.24-1.12 (m, 2H); ${ }^{13} \mathrm{C}$ NMR (126 MHz, $\left.\mathrm{CDCl}_{3}\right) \delta 167.06,156.27$, $154.39,150.21,142.80,138.62,132.98,132.77,129.90,128.67$, $128.58,128.02$, 127.66, 127.47, 127.13, 127.03, 126.20, 125.27, $124.00,123.84,123.25,122.11,116.40,115.47,114.74,114.12$, 112.82, 103.15, 68.22, 65.71, 49.97, 37.34, 24.77, 24.23, 18.63; HRMS $\left(\mathrm{ESI}^{+}\right) \mathrm{m} / \mathrm{z}$ calculated for $\mathrm{C}_{42} \mathrm{H}_{41} \mathrm{NO}_{7}:[\mathrm{M}+\mathrm{H}]^{+}=672.2961$, found: $[\mathrm{M}+\mathrm{H}]^{+}=672.2937$.

\section{Conflicts of interest}

There are no conflicts to declare.

\section{Acknowledgements}

We thank the Shandong Provincial Natural Science Foundation (ZR2017MB052, ZR2017MB060), the Natural Science Foundation of China (21501085), and the Liaocheng University Funds for Young Scientists (31805) for financial support. We thank Dr Tian Zhang (School of Chemistry and Chemical Engineering, Shandong University of Technology) for the calculation part of the fluorescence spectrum.

\section{Notes and references}

1 Photophysics of Aromatic Molecules, ed. J. B. Birks, Wiley, London, 1970.

2 J. Mei, N. L. C. Leung, R. T. K. Kwok, J. W. Y. Lam and B. Z. Tang, Chem. Rev., 2015, 115, 11718-11940.

3 B. Z. Tang, X. Zhan, G. Yu, P. P. Sze Lee, Y. Liu and D. Zhu, J. Mater. Chem., 2001, 11, 2974-2978.

4 B. Xu, J. Zhang, S. Ma, J. Chen, Y. Dong and W. Tian, Prog. Chem., 2013, 25, 1079-1089.

5 F. D. Lewis and B. E. Cohen, J. Phys. Chem., 1994, 98, 1059110597.

6 Q. K. Qi, L. Huang, R. Q. Yang, J. Li, Q. L. Qiao, B. Xu, W. J. Tian, X. G. Liu and Z. C. Xu, Chem. Commun., 2019, 55, 1446-1449.

7 J. R. Larson, J. W. Petrich and N. C. Yang, J. Am. Chem. Soc., 1982, 104, 5000-5002.

8 T. Xu, Y. X. Zhang, B. Wang, C. C. Huang, I. Murtaza, H. Meng and L. S. Liao, ACS Appl. Mater. Interfaces, 2017, 9, 2701-2710.

9 X. Y. Wang, L. Liu, S. X. Zhu, J. H. Peng and L. D. Li, RSC Adv., 2017, 7, 40842-40848.

10 B. B. Correia, T. R. Brown, J. H. Reibenspies, H. S. Lee and R. D. Hancock, Eur. J. Inorg. Chem., 2018, 3736-3747.

11 S. Abraham and R. G. Weiss, J. Am. Chem. Soc., 2011, 133, 19250-19256.

12 T. M. Safko, M. M. Faleiros, T. D. Z. Atvars and R. G. Weiss, J. Phys. Chem. A, 2016, 120, 3983-3991.

13 P. Hrdlovič, L. Horinová and Š. Chmela, Can. J. Chem., 1995, 73, 1948-1954.

14 A. M. Swinnen, M. Van der Auweraer, F. C. De Schryver, K. Nakatani, T. Okada and N. Mataga, J. Am. Chem. Soc., 1987, 109, 321-330.

15 L. Pu, Acc. Chem. Res., 2017, 50, 1032-1040.

16 E. M. Sánchez-Carnerero, F. Moreno, B. L. Maroto, A. R. Agarrabeitia, M. J. Ortiz, B. G. Vo, G. Muller and S. de La Moya, J. Am. Chem. Soc., 2014, 136, 3346-3349.

17 Y. Sheng, D. Shen, W. J. Zhang, H. X. Zhang, C. J. Zhu and Y. X. Cheng, Chem.-Eur. J., 2015, 21, 13196-13200.

18 K. Li, J. C. Cui, Z. R. Yang, Y. M. Huo, W. Z. Duan, S. W. Gong and Z. P. Liu, Dalton Trans., 2018, 47, 15002-15008.

19 W. Z. Duan, Q. S. Liu, Y. M. Huo, J. C. Cui, S. W. Gong and Z. P. Liu, Org. Biomol. Chem., 2018, 16, 4977-4984. 
20 Q. S. Liu, X. Q. Wang, H. Yan, Y. P. Wu, Z. Y. Li, S. W. Gong, P. Liu and Z. P. Liu, J. Mater. Chem. C, 2015, 3, 2953-2959.

21 H. Li, D. L. Zhang, M. N. Gao, L. M. Huang, L. G. Tang, Z. J. Li, X. Y. Chen and X. Z. Zhang, Chem. Sci., 2017, 8, 2199-2203.

22 L. L. Jin, Y. Z. Huang, H. W. Jing, T. Chang and P. Yan, Tetrahedron: Asymmetry, 2008, 19, 1947-1953.

23 Y. P. Wu, S. S. Wang, Z. F. Li, Z. Shen and H. Lu, J. Mater. Chem. C, 2016, 4, 4668-4674.

24 J. P. Dinnocenzo, A. Mark and S. Farid, J. Org. Chem., 2019, 84, 7840-7850.

25 H. K. Zhang, X. Y. Zheng, N. Xie, Z. K. He, J. K. Liu, N. L. C. Leung, Y. L. Niu, X. H. Huang, K. S. Wong, R. T. K. Kwok, H. H. Y. Sung, L. D. Williams, A. J. Qin, J. W. Y. Lam and B. Z. Tang, J. Am. Chem. Soc., 2017, 139, 16264-16272.

26 M. J. Frisch, G. W. Trucks, H. B. Schlegel, G. E. Scuseria, M. A. Robb, J. R. Cheeseman, J. A. Montgomery Jr, T. Vreven, K. N. Kudin, J. C. Burant, J. M. Millam, S. S. Iyengar, J. Tomasi, V. Barone, B. Mennucci, M. Cossi, G. Scalmani, N. Rega, G. A. Petersson, H. Nakatsuji, M. Hada, M. Ehara, K. Toyota, R. Fukuda, J. Hasegawa, M. Ishida, T. Nakajima, Y. Honda, O. Kitao, H. Nakai, M. Klene, X. Li, J. E. Knox, H. P. Hratchian, J. B. Cross, V. Bakken, C. Adamo, J. Jaramillo, R. Gomperts, R. E. Stratmann, O. Yazyev, A. J. Austin, R. Cammi, C. Pomelli, J. W. Ochterski, P. Y. Ayala, K. Morokuma, G. A. Voth, P. Salvador, J. J. Dannenberg, V. G. Zakrzewski, S. Dapprich, A. D. Daniels, M. C. Strain, O. Farkas, D. K. Malick, A. D. Rabuck, K. Raghavachari,
J. B. Foresman, J. V. Ortiz, Q. Cui, A. G. Baboul, S. Clifford, J. Cioslowski, B. B. Stefanov, G. Liu, A. Liashenko, P. Piskorz, I. Komaromi, R. L. Martin, D. J. Fox, T. Keith, M. A. Al-Laham, C. Y. Peng, A. Nanayakkara, M. Challacombe, P. M. W. Gill, B. Johnson, W. Chen, M. W. Wong, C. Gonzalez and J. A. Pople, Gaussian 03, Revision D.01, Gaussian, Inc., Wallingford CT, 2004.

27 T. Zhang, G. Z. Zhu, L. L. Lin, J. L. Mu, B. Ai, Y. C. Li and S. P. Zhuo, Org. Electron., 2019, 68, 264-270.

28 T. Zhang, W. Shi, D. Wang, S. P. Zhuo, Q. Peng and Z. G. Shuai, J. Mater. Chem. C, 2019, 7, 1388-1398.

29 E. V. Fedorenko, A. G. Mirochnik and A. Y. Beloliptsev, J. Lumin., 2017, 185, 23-33.

30 H. Li, Y. Guo, G. X. Li, H. P. Xiao, Y. X. Lei, X. B. Huang, J. X. Chen, H. Y. Wu, J. C. Ding and Y. X. Cheng, J. Phys. Chem. C, 2015, 119, 6737-6748.

31 D. P. Shelar, S. R. Patil, R. V. Rote, R. B. Toche and M. N. Jachak, J. Fluoresc., 2011, 21, 1033-1047.

32 M. G. Ren, K. Zhou, L. Wang, K. Y. Liu and W. Y. Lin, Sens. Actuators, B, 2018, 262, 452-459.

33 T. T. Divya, K. Ramshad, V. C. Saheer and L. Chakkumkumarath, New J. Chem., 2018, 42, 20227-20238.

34 H. K. Zhang, H. K. Li, J. Wang, J. Z. Sun, A. J. Qin and B. Z. Tang, J. Mater. Chem. C, 2015, 3, 5162-5166.

35 H. K. Zhang, X. Y. Zheng, R. T. K. Kwok, J. Wang, N. L. C. Leung, L. Shi, J. Z. Sun, Z. Y. Tang, J. W. Y. Lam, A. J. Qin and B. Z. Tang, Nat. Commun., 2018, 9, 4961-4968. 36 F. Qian, C. Zhang, Y. Chang, W. He, X. Gao, P. Hu and Z. Guo, J. Am. Chem. Soc., 2009, 131, 1460. 